\title{
IMPORTÂNCIA ANATOMOCIRÚRGICA DAS CARACTERÍSTICAS MACROSCÓPICAS, LOCALIZAÇÃO E SUPRIMENTO VASCULAR DAS GLÂNDULAS PARATIREÓIDES CERVICAIS
}

\author{
ANATOMIC AND SURGICAL IMPORTANCE OF MACROSCOPIC \\ CHARACTERISTICS, LOCATIONAND VASCULAR SUPPLY OF CERVICAL \\ PARATHYROID GLANDS
}

\author{
João Bosco Lopes Botelho, TCBC-AM ${ }^{1}$ \\ Anderson R. S. Cançado ${ }^{2}$ \\ Elane Araujo de Sousa ${ }^{3}$
}

\begin{abstract}
RESUMO: Objetivos: A importância anatômica e cirúrgica das glândulas paratireóides, notadamente, no curso das tireoidectomias continua viva e despertando interesse científico. Por outro lado, são raros os trabalhos científicos sobre a investigação da anatomia das paratireóides. Dessa forma, o objetivo deste trabalho é contribuir para estabelecer essa ponte anatomocirúrgica. Método: Estudo macro e microscópico das glândulas paratireóides dissecadas nas peças anatômicas de dezenove cadáveres, todos do sexo masculino e com idade entre 20 e 60 anos. Na abordagem do suprimento vascular foi utilizada a técnica de corrosão para identificar a vascularização e a glândula tireóide adotada como referência espacial na localização das paratireóides. Resultados: Foram identificadas na macro e microscopia 76 glândulas paratireóides cervicais. Trinta e quatro (44,73\%) possuíam a coloração vermelho-amarelada, $26(34,21 \%)$ a cor preto-acinzentada e dezesseis (21,06\%) a cor castanho-amarelada. O tamanho encontrado ficou entre 3 e $15 \mathrm{~mm}$, prevalecendo o intervalo de 4a 6,9mm em 43 (56,58\%) glândulas. Foram encontradas de duas a seis paratireóides por cadáver, prevalecendo o número de quatro (47,37\%) em nove necrópsias. Quarenta e duas (55,26\%) glândulas localizavam-se superior à tireóide e 34 (47,74\%) inferiormente. Os moldes da vascularização das paratireóides após a corrosão demonstraram que os capilares provenientes das artérias tireóideas superiores e inferiores se unem próximo à glândula. Conclusões: Com forte influência no curso das tireoidectomias, o estudo evidenciou que as glândulas paratireóides cervicais superiores e inferiores podem ser encontradas em diferentes posições frente à tireóide com maior ou menor intimidade em relação à cápsula tireóidea e que a irrigação vascular de uma paratireóide não é proveniente apenas de uma artéria.
\end{abstract}

Descritores: Glândula tireóide; Glândulas paratireóides.

\section{INTRODUÇÃO}

As cirurgias na glândula tireóide podem, em determinadas circunstâncias, causar danos para as glândulas paratireóides e/ou aos seus suprimentos vasculares. A expressão clínica desse acontecimento intra-operatório, manifesta no pós-operatório imediato, pode ser avaliada por meio dos sinais e sintomas clínicos do hipoparatireoidismo, as dosagens séricas do cálcio, do fósforo e do PTH. O relato da incidência do hipoparatireoidismo, seja transitório ou permanente, como uma das possíveis complicações pós-ope-

1. Prof. Dr. LD da Universidade do Estado do Amazonas; Professor Titular aposentado da Universidade Federal do Amazonas (UFAM); Membro da Academia Amazonense de Medicina.

2. Acadêmico de Medicina e Monitor da Disciplina de Clínica Cirúrgica I da UFAM.

3. Acadêmica de Medicina e Monitora da Disciplina de Anatomia da UFAM.

Recebido em 06/11/2003

Aceito para publicação em10/02/2004

Trabalho realizado na Disciplina de Anatomia do Instituto de Ciências Biológicas da UFAM e no Serviço de Cirurgia de Cabeça e Pescoço do Hospital Universitário Getúlio Vargas da UFAM; Prêmio Prof. Garcia do Prado de Anatomia Humana de 2002. 
ratórias das tireoidectomias parciais ou totais, varia consideravelmente entre publicações, dependendo do critério para montar o diagnóstico: de 0,2 a 30\% das ressecções parciais das glândulas tireóides ${ }^{1-7}$.

A literatura é abundante quanto às manifestações clínicas do hipoparatireoidismo, transitório ou permanente, no pós-operatório das tireoidectomias, sem dúvida, com maior possibilidade de ocorrência nas totais em comparação com as parciais. Contudo, esse fato não deve constituir, por si mesmo, empecilho para a totalização das tireoidectomias parciais, tanto na recidiva do bócio quanto nos tumores malignos $^{2}$.

Dessa forma, os estudos anatomocirúrgicos das glândulas paratireóides quanto ao número, tamanho, forma, cor, localização e suprimento vascular podem, claramente, contribuir para evitar o trauma ou a remoção inadvertida.

\section{MÉTODO}

Foram analisadas as paratireóides e as suas relações com a glândula tireóide em 19 cadáveres, do sexo masculino e com idade entre 20 e 60 anos. As peças anatômicas foram obtidas no Instituto Médico Legal, de Manaus, mediante autorização documentada da Direção dessa instituição pública, de acordo com a Lei n. 8501, que autoriza a utilização dos corpos quando não reclamados, para fins de estudos ou pesquisas científicas. Seguem-se as seguintes etapas para obtenção das peças anatômicas:

1. Incisão mediana na cútis anterior do pescoço, ao nível da fúrcula esternal até um centímetro acima do osso hióide, para que fosse possível abordar a bifurcação da carótida comum e conseqüentemente a carótida externa com o seu ramo tireóidea superior. A partir dessa incisão inicial, outras duas com trajeto medio-lateral, bilateralmente, das clavículas às mastóides completaram os acessos às artérias tireóides inferiores e aos feixes vásculo-nervosos cervicais. A pele foi rebatida no sentido medio-lateral seguida do mesmo procedimento para os músculos platisma e esternocleidomastóideo com o objetivo de obter a clara visualização das estruturas vasculares do pescoço. O procedimento de exposição foi complementado com a incisão transversal ao nível da borda inferior da mandíbula, de tal maneira que atingisse até o esôfago. Na porção inferior, o esôfago foi incisado em sentido inclinado, aproximadamente $30^{\circ}$, com a finalidade de abordar os vasos do mediastino superior e anterior. A peça anatômica foi removida e constituída em monobloco: tireóide, traquéia, esôfago, vasos, nervos, tecido muscular, linfático e conectivo (Figura 1);

2. Dissecção minuciosa das peças anatômicas com a identificação e registro fotográfico das glândulas paratireóides quanto à coloração, tamanho, forma, superfície, vascularização e tecido circundante;

3. Para melhor detalhamento da vascularização os vasos foram injetados com o corante obtido por meio da mistura de vinte gramas de acrílico em pó autopolimerizante e tinta automotiva (azul arara, vermelho Ferrari ou amarelo) de acordo com a coloração desejada: na traquéia, o corante branco; nas paratireóides, o amarelo; nas artérias, o vermelho e nas veias, o azul;

4. Depois de solidificado o material injetado, o bloco estava pronto para ser mergulhado em ácido clorídrico a $90 \%$ (técnica de corrosão), permanecendo entre 20 e 60 horas, tempo suficiente para a corrosão de todo tecido existente no bloco e exposição dos moldes (Figuras 2 e 3).

O ponto central do inédito trabalho consistiu na investigação de um conjunto de 76 glândulas paratireóides, de conteúdo puramente científico, voltado inteiramente para o enriquecimento dos estudos nessa direção já existentes, mas com conotação diferenciada.

Para condensação dos resultados pesquisados não foi possível seguir-se um padrão rígido de comparação dos elementos de um grupo em relação a outros, de vez que os dados alcançados nem sempre apresentavam um padrão uniforme de comportamento, com algumas exceções, impossibilitando aplicarse por extensão, a análise de um conjunto de peças às demais.

Nessas circunstâncias, como metodologia de exposição dos dados estatísticos da pesquisa, sempre que possível, foi utilizado o mecanismo matemático do cálculo proporcional, através da aplicação e indicação percentual das partes, em relação ao todo investigado. 


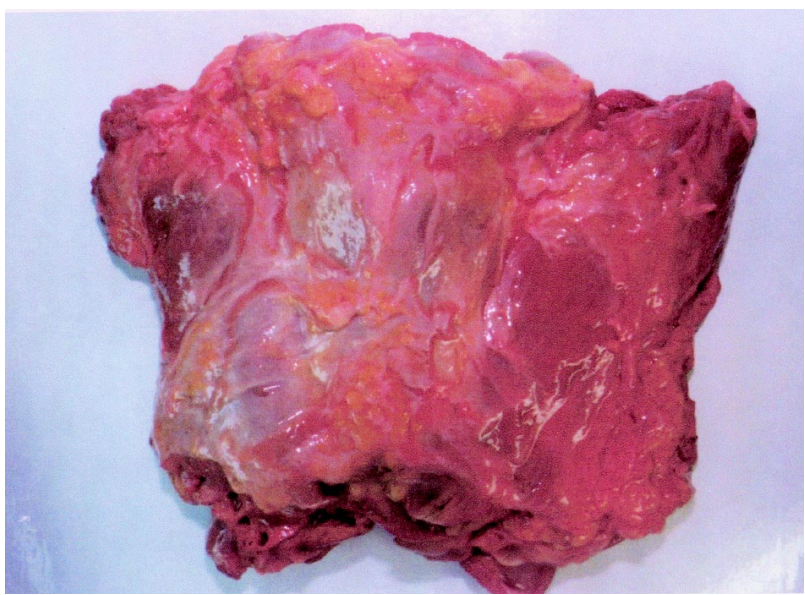

Figura 1 - Vista anterior da peça anatômica em monobloco removida do pescoço.

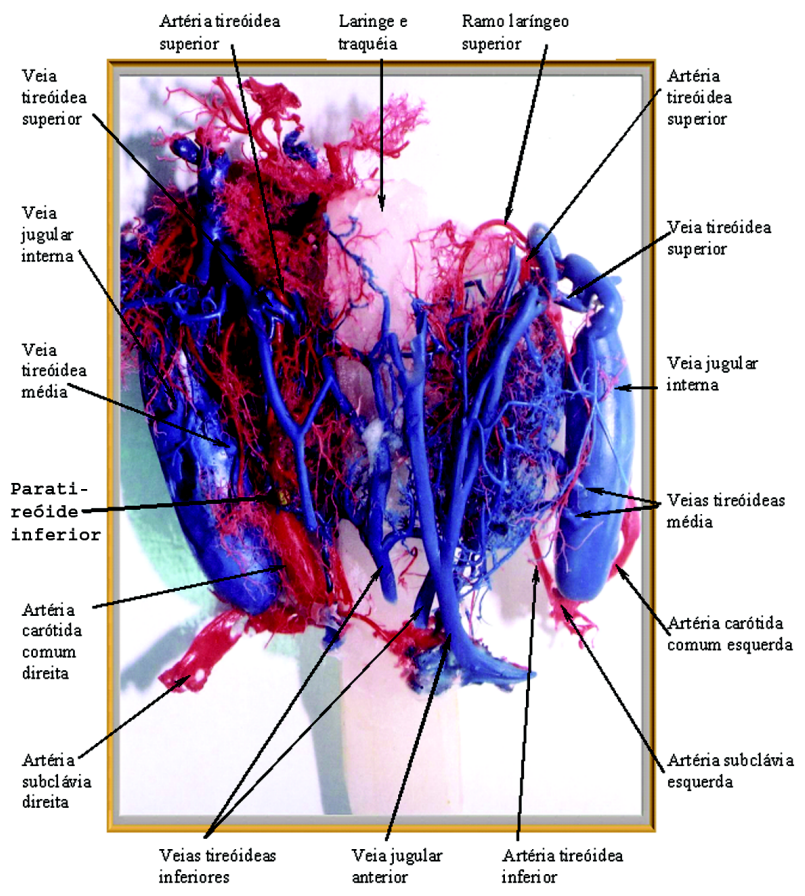

Figura 2 - Vista anterior do bloco corroído, expondo os moldes de vascularização, traquéia e paratireóides. Visualiza-se perfeitamente a trama vascular da tireóide; vêem-se as veias tireóidea superior e inferior de ambos os lados e suas tributárias e a paratireóide infero-anterior do lado esquerdo.

\section{RESULTADOS}

\section{Características Macroscópicas}

Forma: variável destacando-se a ovóide (forma predominante - Figura 4), globosa, assimétrica e achatada.

Superfície: todas as 76 (100\%) glândulas paratireóides apresentaram superfície lisa. $\mathrm{Na}$

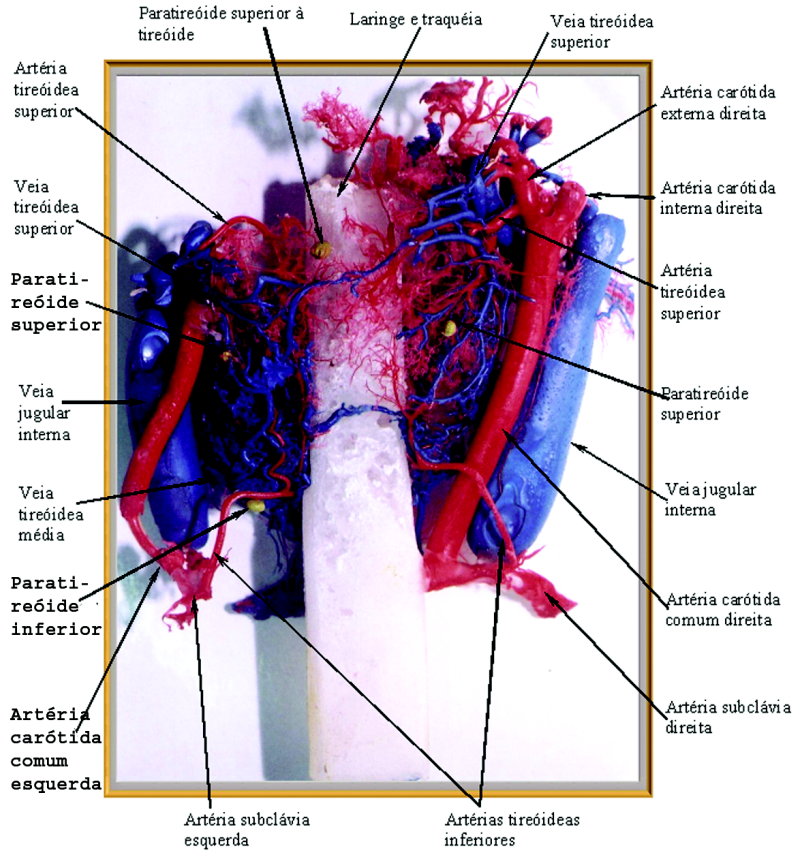

Figura 3 - Vista posterior do bloco corroído, expondo os moldes de vascularização, traquéia e paratireóides. Visualiza-se perfeitamente a trama vascular da tireóide; vêem-se as veias tireóidea superior e inferior de ambos os lados e suas tributárias e as quatro paratireóides posteriores.

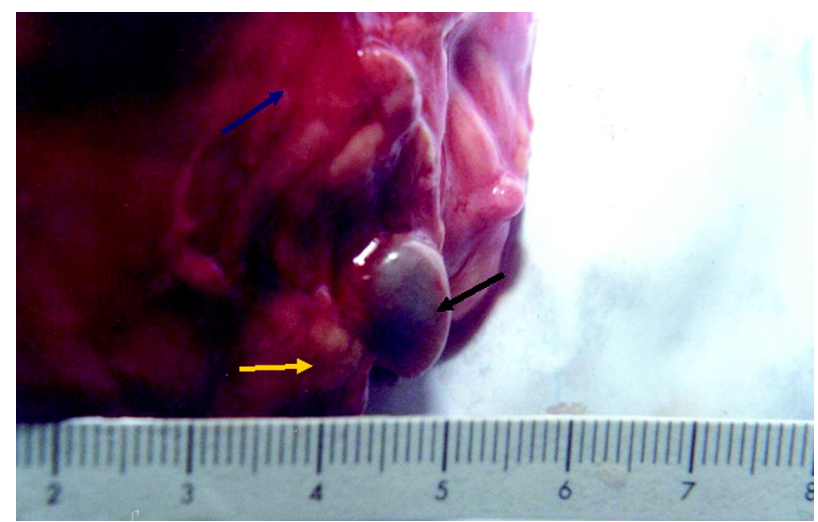

Figura 4 - A seta preta representa a paratireóide de forma ovóide, localizada no terço inferior e posterior da tireóide, a seta amarela tecido tireoideano e a seta azul tecido conjuntivo.

microscopia, em 18 (23,68\%) foi possível observar o revestimento constituído pela cápsula própria.

Tecido circundante: foi identificado com uma coloração amarelada, constituída de tecido conjuntivo e adiposo, identificado no microscópico óptico. Esse tecido estava disposto circundando e aderido em 44 (57,89\%) às glândulas paratireóides; não totalmente aderido em 12 (15,79\%) e circundando e encobrindoa totalmente em 20 (26,32\%). 
Cor: predominaram três cores: 34 (44,73\%) paratireóides vermelho-amareladas, 26 (34,21\%) preto-acinzentadas e $16(21,06 \%)$ paratireóides castanho-amareladas.

Tamanho: Foram medidas duas dimensões das paratireóides: a altura e a largura. A terceira, a espessura, não foi feita, pois para que fosse realizada a contento obrigaria a dissecção completa da glândula, prejudicando o estudo da vascularização. Foram dissecadas mais cuidadosamente apenas as que estavam envoltas no tecido periglandular, até o ponto de serem visualizadas.

A menor paratireóide encontrada estava localizada no terço inferior do lobo esquerdo da tireóide e tinha 3mm de largura por 3mm de altura; já a maior estava localizada no terço superior do lobo direito e tinha $7 \mathrm{~mm}$ de largura por $15 \mathrm{~mm}$ de altura (Tabela 1 ).

Tabela 1 - Relação entre o tamanho e a localização da paratireóide (em relação a tireóide - lobo direito ou esquerdo).

\begin{tabular}{ccc}
\hline $\begin{array}{c}\text { Tamanho da } \\
\text { Paratireóide }\end{array}$ & Lobo Direito & Lobo Esquerdo \\
\hline $03-3,9 \mathrm{~mm}$ & 02 & 01 \\
$04-4,9 \mathrm{~mm}$ & 07 & 08 \\
$05-5,9 \mathrm{~mm}$ & 10 & 04 \\
$06-6,9 \mathrm{~mm}$ & 09 & 05 \\
$07-7,9 \mathrm{~mm}$ & 06 & 02 \\
$08-8,9 \mathrm{~mm}$ & 03 & 04 \\
$09-9,9 \mathrm{~mm}$ & 01 & 01 \\
$10-10,9 \mathrm{~mm}$ & 03 & 04 \\
$11-11,9 \mathrm{~mm}$ & 01 & 02 \\
$12-12,9 \mathrm{~mm}$ & 02 & - \\
$13-15,0 \mathrm{~mm}$ & - & 01 \\
\hline TOTAL & $\mathbf{4 4}$ & $\mathbf{3 2}$ \\
\hline
\end{tabular}

Número: quatro paratireóides cervicais foram encontradas em nove peças anatômicas (47,37\%); seis, em três peças $(15,79 \%)$; cinco, em duas peças (10,53\%); três, em duas peças $(10,53 \%)$ e, por fim, duas, em três peças (15,79\%) (Tabela 2).

Localização: Os critérios da localização das paratireóides foram atados em relação à tireóide: superiormente, no terço médio, no terço inferior da tireóide e inferiormente (Figura 5).
Suprimento Vascular: por meio da técnica de corrosão, explicitada anteriormente, visualizou-se o molde dos vasos que irrigam e drenam a tireóide e as estruturas contíguas. Com o molde solidificado foi possível observar o arcabouço da tireóide e mediante as anotações feitas durante a identificação macroscópica das glândulas paratireóides, juntamente com o registro fotográfico, teve-se sua provável localização e conseqüentemente, os possíveis vasos que as suprem.

Tabela 2 - Relação entre o número e a porcentagem de glândulas paratireóides e um determinado intervalo de altura, estipulado aleatoriamente para fins didáticos.

\begin{tabular}{ccc}
\hline $\begin{array}{c}\text { Tamanho da } \\
\text { Paratireóide }\end{array}$ & $\begin{array}{c}\text { Número de } \\
\text { Paratireóides }\end{array}$ & $\begin{array}{c}\text { Porcentagem de } \\
\text { Paratireóides }\end{array}$ \\
\hline $03-3,9 \mathrm{~mm}$ & 03 & $03,95 \%$ \\
$04-4,9 \mathrm{~mm}$ & 15 & $19,74 \%$ \\
$05-5,9 \mathrm{~mm}$ & 14 & $18,42 \%$ \\
$06-6,9 \mathrm{~mm}$ & 14 & $18,42 \%$ \\
$07-7,9 \mathrm{~mm}$ & 08 & $10,53 \%$ \\
$08-8,9 \mathrm{~mm}$ & 07 & $09,21 \%$ \\
$09-9,9 \mathrm{~mm}$ & 02 & $02,63 \%$ \\
$10-10,9 \mathrm{~mm}$ & 07 & $09,21 \%$ \\
$11-11,9 \mathrm{~mm}$ & 03 & $03,95 \%$ \\
$12-12,9 \mathrm{~mm}$ & 02 & $02,63 \%$ \\
$13-15,0 \mathrm{~mm}$ & 01 & $01,31 \%$ \\
\hline TOTAL & $\mathbf{7 6}$ & $\mathbf{1 0 0 , 0 0 \%}$ \\
\hline
\end{tabular}

Em alguns moldes, as vascularizações das paratireóides superiores e inferiores foram claramente identificadas, com os ramos da artéria tireóidea superior, especificamente, o ramo laríngeo superior, ramo cranial dorsal e ramo cranial ventral; os ramos da artéria tireóide inferior, os dois ramos tireóideos caudais e os ramos esofágicos, irrigando as paratireóides superiores e inferiores.

Em relação à drenagem venosa de 36 paratireóides, sete (19,44\%) eram drenadas, simultaneamente, pelas veias tireóideas inferiores e tributárias; seis $(16,66 \%)$ pelas veias tireóideas superiores e tributárias; seis $(16,66 \%)$ somente pelas veias tireóideas superiores; seis $(16,66 \%)$ somente pelas veias tireóideas inferiores; em três $(8,33 \%)$ pelas veias tireóideas superiores e inferiores; em dois (5,55\%) pelas veias tireóidea superior, laríngea e traqueal; 
em uma $(2,77 \%)$ pela tributária da veia tireóidea superior e em cinco $(13,89 \%)$ não foi possível observar a vascularização de drenagem venosa (Figura 2 e 3$)$.

Peso: Das 76 glândulas paratireóides estudadas, dezoito (23,68\%) foram dissecadas para a obtenção do peso e realização do exame histológico, observando-se um intervalo de 01 a $43 \mathrm{mg}$, que foram divididos em cinco grupos visto a seguir:

a. De 1 a 9mg: sete (38,88\%) paratireóides;

b. De 10 a 19mg: cinco (27,78\%) paratireóides;

c. De 20 a 29mg: duas (11,11\%) paratireóides;

d. De 30 a 39mg: duas (11,11\%) paratireóides;

e. De 40 a 49mg: duas (11,11\%) paratireóides.

\section{DISCUSSÃO}

Pelos achados, notadamente, no que diz respeito à presença do tecido circundante, não tendo sido encontrado sobre esse assunto qualquer referência na literatura, envolvendo de modo completo a glândula paratireóide em vinte glândulas ou 26,32\% desse estudo e a variedade das formas, constituem elementos anatomocirúrgicos da maior importância, já que podem dificultar a identificação no curso das tireoidectomias sejam as parciais ou as totais tecnicamente bem conduzidas.

Sob essa perspectiva, mesmo aos mais hábeis cirurgiões, após a tireoidectomia total ou parcial, com a peça cirúrgica nas mãos, é conveniente examiná-la muito atentamente com o objetivo de identificar alguma paratireóide que possa ter permanecido aderida à tireóide ${ }^{3}$, para, em seguida, delicadamente, incisá-la em vários sentidos sem fragmentá-la e proceder ao re-implante na musculatura cervical lateral, na intimidade do músculo esternocleidomastóideo.

De igual importância é o tamanho das paratireóides. De certo modo, é razoável supor que quanto maior, mais fácil será a identificação no campo cirúrgico. Nesse estudo a menor alcançou $3 \mathrm{~mm}$ de largura por $3 \mathrm{~mm}$ de altura e se associadas ao tecido circundante denso, sem dúvida, oferecem maior dificuldade ao isolamento cirúrgico.
Quanto ao número das paratireóides - quatro paratireóides cervicais em nove peças anatômicas (47,37\%); seis, em três peças (15,79\%); cinco, em duas peças $(10,53 \%)$ cadáveres; três, em duas peças $(10,53 \%)$ e duas, em três peças (15,79\%) - podem explicar as razões da ocorrência de:

a. Nos pacientes com duas ou três paratireóides, o maior número de hipoparatireoidismo com exuberante manifestação clínica no pós-operatório de tireoidectomias totais ou parciais bem conduzidas;

b. Nos pacientes com quatro ou mais paratireóides, menor número de hipoparatireoidismo mesmo com mais manuseio das glândulas paratireóides que, normalmente, ocorre nas tireoidectomias totais.

Em relação à cor das glândulas paratireóides, qualquer que seja ela, um dado precioso no campo cirúrgico está atado à mudança rápida da coloração, tornando-se mais escura, após a manipulação cirúrgica ${ }^{4}$.

Como na literatura, os achados da pesquisa mostraram as paratireóides superiores mantendo as localizações mais homogêneas em relação às inferiores ${ }^{7}$. Como a maioria das paratireóides estava posterior à tireóide, precisamente, cinqüenta e nove $(77,64 \%)$, sendo sete $(11,84 \%)$ de localização superior; cinco, anterior e lateral $(6,58 \%)$ e três (3,95\%), inferior, no curso das tireoidectomias totais ou parciais, após a ligadura dos pedículos superiores, torna-se da maior importância a firme mobilização do parênquima glandular no sentido látero-medial, para o acesso adequado tanto à artéria tireóidea quanto à paratireóide inferior e ao nervo laríngeo recorrente ${ }^{4,5}$ (Figura 6).

Em relação à vascularização arterial, em todas as glândulas paratireóides estudadas não foi encontrada, em nenhuma delas, uma artéria específica, denominada por renomados autores, como Halsted e Evans, em 1907, como sendo a artéria paratireóide ${ }^{5}$. Por outro lado, foi possível identificar a exuberante rede de ramos provenientes das artérias superiores e inferiores, respectivamente, nutrindo as paratireóides superiores e as inferiores. A drenagem venosa, do mesmo modo em todas elas, realizada por meio das tributárias das veias tireóideas superiores e in- 


\section{Porção anterior e lateral}

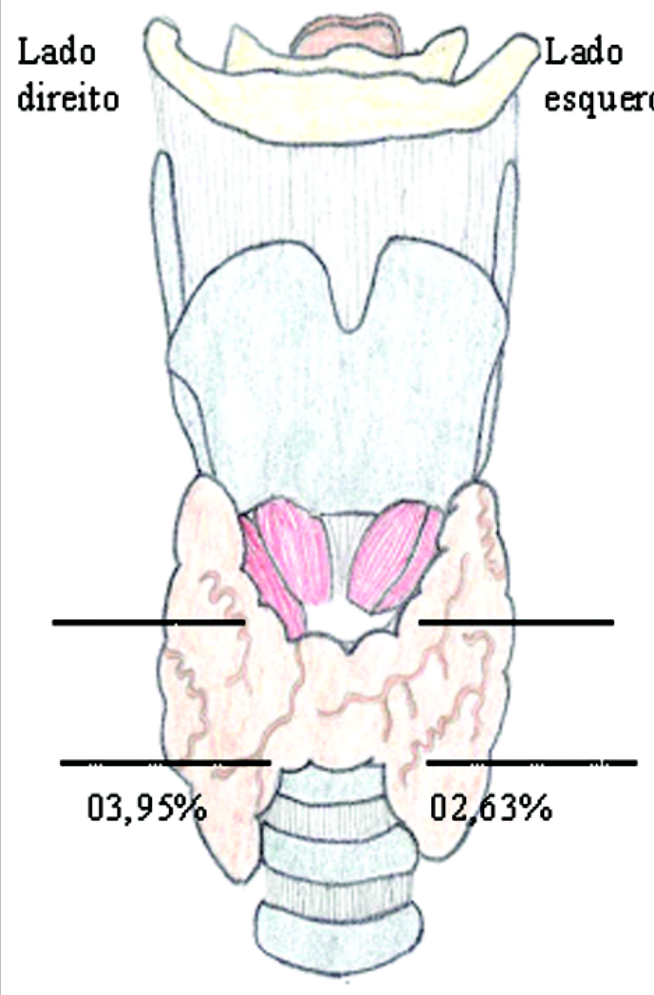

\section{Porção posterior}

Superiormente

Lado esquerdo

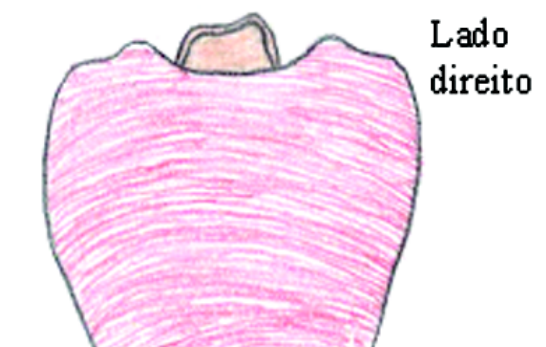

Terço superior

Terço médio

Terço inferior

Inferiormente

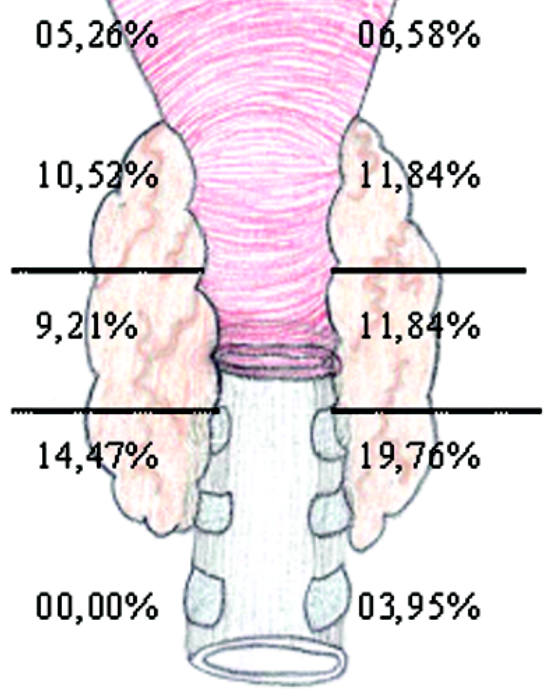

Figura 5 - Representações da porcentagem da localização de todas as 76 paratireóides em relação à tireóide

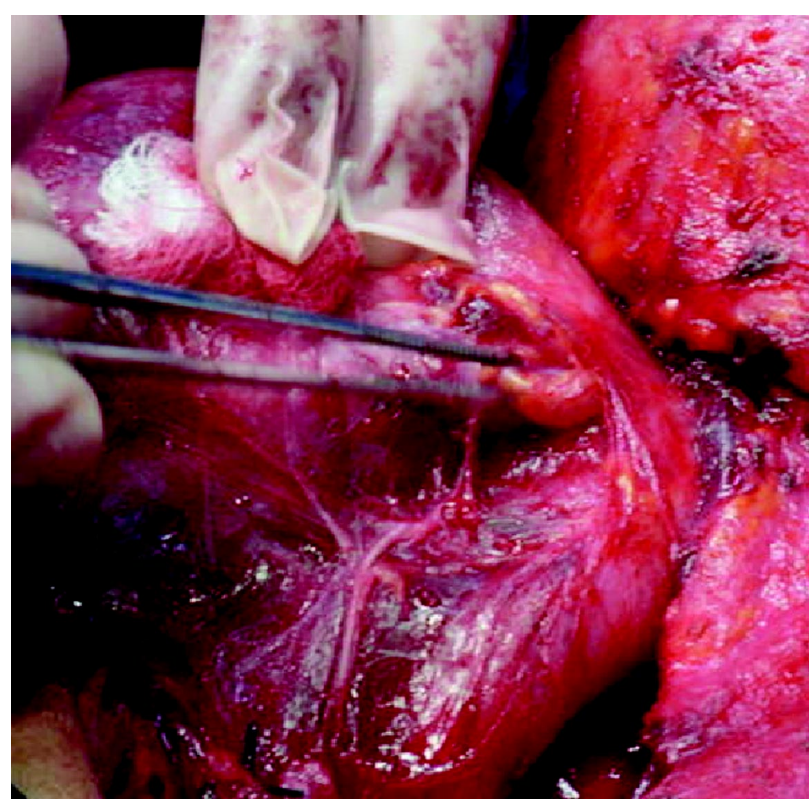

Figura 6 - Mobilização látero-medial da tireóide seguida da identificação da artéria tireóidea inferior, paratireóide e nervo laríngeo recorrente. feriores. Por essa razão bastante clara neste estudo, a inexistência de uma artéria paratireóide, existe a recomendação de evitar a ligadura dos ramos terciários das artérias tireóideas com o objetivo de não comprometer a vascularização das paratireóides ${ }^{6,7}$

Na análise dos pesos das dezoito glândulas dissecadas, obteve-se o intervalo de 1 a 43mg, bastante diferente de trabalho, publicado em 1934, no qual o peso das paratireóides normais variou de 106 a $166 \mathrm{mg}$ nos homens ${ }^{8}$. Contudo, mais próximo de outra publicação, de 1933, cujos pesos ficaram entre 2,7 a $70,6 \mathrm{mg}^{9}$

O melhor conhecimento das características macroscópicas das glândulas paratireóides pode, sem dúvida, facilitar as suas identificações no curso das tireoidectomias totais ou parciais e, conseqüentemente, diminuir os riscos da ocorrência do hipoparatireoidismo pós-operatório. 


\begin{abstract}
Objectives: The anatomic and surgical importance of the parathyroid glands, notably in the course of thyroidectomy still continues alive and awaking scientific interests. On the other hand, there are scarce scientific studies about the investigation of parathyroid glands anatomy. The main objective of this study is to contribute to establish these anatomic and surgical connections. Methods: The macro and microscopic studies of the parathyroid glands dissected in anatomic parts from nineteen corpses, all male between 20 and 60 years old. To approach the vascular supply, it was used an erosion technique to identify the blood vessels and the thyroid gland adopted as a space reference in the parathyroid glands location. Results: There were identified in macro and microscopy 76 cervical parathyroid glands. Thirty-four (44.73\%) had a yellow-red colouring, 26 (34.21\%) a grey-black colouring and sixteen (21.06\%) a yellow-tan colouring. The size was between 3 to $15 \mathrm{~mm}$, prevailing the interval of 4 to $6.9 \mathrm{~mm}$ in $43(56.58 \%)$ glands. There were found from two to six parathyroid glands per corpse, prevailing the number of four in nine (47.37\%) necropsies. Forty-two (55.26\%) parathyroid glands were from the upper and 34 (47.74\%) from the lower thyroid gland. Blood vessels moulds of parathyroid glands after the erosion technique, demonstrated that capillaries prevailing from the upper and lower thyroid arteries join together next to the gland. Conclusion: With strong influence in the course of thyroidectomies, the study showed up that upper and lower cervical parathyroid glands can be found in different positions face to thyroid gland, with greater or smaller intimacy gland is not prevailing of a unique artery.
\end{abstract}

Key Words: Thyroid gland; Parathyroid glands.

\section{REFERÊNCIAS}

1. Thomusch O, Machens A, Sekulla C et al. - The impact of surgical technique on postoperative hypoparathyroidism in bilateral thyroid surgery: a multivariate analysis of 5846 consecutive patients. Surgery, 2003, 133(2):180-185.

2. Hisham AN, Azlina AF, Aina EN, et al. - Total thyroidectomy: the procedure of choice for multinodular goitre. Eur J Surg, 2001, 167(6):403-405.

3. Kato A, Yamada H, Ishinaga $\mathrm{H}$ - Parathyroid function after total or subtotal thyroidectomy. Nippon Jibiinkoka Gakkai Kaiho, 2000, 103(2):160-164

4. Botelho JB, Souza RM, Anjos GS, et al. - Patologia da glândula tireóide. In Botelho JB (Coord.) Otorrinolaringologia e cirurgia de cabeça e pescoço para estudantes. Manaus. Edua, 2000, pp. 325-398.

5. Botelho JB - Pathologie de la glande thyroïde. In Botelho JB, Gehanno P - Otorhinolaryngologie et Chirurgie Cervico-faciale. Paris. Edk, 2002, pp. 61-90.

6. Bergamaschi R, Becouarn G, Ronceray J, et al. Morbidity of thyroid surgery. Am J Surg, 176(1):71-75.

7. Shaha AR, Jaffe BM - Parathyroid preservation during thyroid surgery. Am J Otolaryngol, 1998, 19(2):113-117.

8. Freitas RF. A validade da totalização da tireoidectomia como segunda cirurgia no carcinoma diferenciado da tireóide. Dissertação (Mestrado em Cirurgia). Rio de Janeiro/ Amazonas. Universidade Federal do Rio de Janeiro e Universidade Federal do Amazonas, 2002, $44 \mathrm{p}$.
9. Lo CY, Lam KY - Postoperative hypocalcaemia in patients who did or did not undergo parathyroid autotransplantation during thyroidectomiy: a comparative study. Surgery, 1998, 124(6):1081-1087.

10. Ander S, Johansson K, Smeds S - In situ preservation of the parathyroid glands during operations on the thyroid. Eur J Surg, 1997, 163(1):33-37.

11. Attie JN, Khafif RA - Preservation of parathyroid glands during total thyroidectomy. Improved technic utilizing microsurgery. Am J Surg, 1975, 130(4):399-404.

12. Bliss RD, Gauger PG, Delbridge LW - Surgeon's approach to the thyroid gland : surgical anatomy and the importance of technique. World J Surg, 2000, 24(8):891-897.

13. Cakmakli S, Aydintug S, Erdem E - Post-thyroidectomy hypocalcemia: does arterial ligation play a signicant role? Int Surg, 1992, 77(4):284-286.

14. Gilmour JR, Martins WJ - The weight of the parathyroid glands. J Path Bact, 1937, 44(3):431-462.

15. Welti H. Anatomie chirurcale des parathyroides. Signification de la calcemia le syndrome d’hypoparathyroidisme. Congrès Français de Chirurgie, 42a . Session. Secretariat de L'association. Paris. 1933, pp. 33-139.

Endereço para correspondência:

João Bosco Botelho

Av. Eduardo Ribeiro, 520 - sala 705

Centro

69010-000 - Manaus -AM 